Toshiyuki Ikeda • Akihiko Mabuchi • Akira Fukuda

Hisatada Hiraoka • Akira Kawakami • Seizo Yamamoto

Hideto Machida • Yoshio Takatori • Hiroshi Kawaguchi

Kozo Nakamura • Shiro Ikegawa

\title{
Identification of sequence polymorphisms in two sulfation-related genes, PAPSS2 and SLC26A2, and an association analysis with knee osteoarthritis
}

Received: May 7, 2001 / Accepted: June 21, 2001

\begin{abstract}
Osteoarthritis (OA) is one of the most common musculoskeletal disorders and is characterized by degeneration of articular cartilage. Sulfation of extracellular matrix proteins in articular cartilage is an important step in maintaining normal cartilage metabolism. Two sulfationrelated genes have been reported as the causal genes of severe chondrodysplasias: mutations in PAPSS2 (3'phosphoadenosine $5^{\prime}$-phosphosulfate synthase 2) cause spondylo-epimetaphyseal dysplasia (SEMD), and mutations in SLC26A2 (solute carrier family 26, member 2) cause diastrophic dysplasia. Given their critical roles in cartilage metabolism and the severe phenotypes that result from mutations in these genes, we examined PAPSS 2 and $S L C 26 A 2$ as candidate susceptibility loci for OA. We identified sequence polymorphisms in the coding and core promoter regions of these genes and analyzed their potential association with knee OA within the Japanese population. Ten sequence polymorphisms were detected in PAPSS2 and five in SLC26A2. An association analysis showed suggestive association of one minor polymorphism in the promoter region of $S L C 26 A 2$. This 4-bp adenine deletion allele, del4A, was over-represented in knee OA $(P=0.043$, odds ratio $=3.43$ ) and is thought to confer a minor susceptibility to knee OA within the Japanese population. Haplotype analysis showed no evidence of association with the
\end{abstract}

T. Ikeda $\cdot$ A. Mabuchi $\cdot$ S. Ikegawa $(\square)$

Laboratory for Bone and Joint Diseases, SNP Research Center,

RIKEN (The Institute of Physical and Chemical Research),

c/o Institute of Medical Science, University of Tokyo,

4-6-1 Shirokanedai, Minato-ku, Tokyo 108-8639, Japan

Tel./Fax +81-3-5449-5393

e-mail: sikegawa@ims.u-tokyo.ac.jp

A. Fukuda $\cdot$ H. Hiraoka $\cdot$ H. Machida $\cdot$ Y. Takatori $\cdot$ H. Kawaguchi $\cdot$ K. Nakamura

Department of Orthopaedic Surgery, The University of Tokyo,

Tokyo, Japan

A. Kawakami

Department of Orthopedics Surgery, Tokyo Teishin Hospital, Tokyo, Japan

S. Yamamoto

Department of Orthopedic Surgery, Tokyo Metropolitan Geriatric

Hospital, Tokyo, Japan two genes, however, excluding them as major susceptibility loci for knee OA.

Key words Association analysis · Osteoarthritis · Polymorphisms - Sulfation - Haplotype analysis - PAPSS2 (3'phosphoadenosine $5^{\prime}$-phosphosulfate synthase 2) . SLC26A2 (solute carrier family 26 , member 2)

\section{Introduction}

Osteoarthritis (OA) is one of the most common musculoskeletal disorders and is characterized by degeneration of articular cartilage. The most common type of OA, idiopathic OA, usually occurs in the fifth or sixth decades of life, accompanied by pain and functional impairment. Idiopathic $\mathrm{OA}$ is a common, polygenic disease caused by the interaction of environmental and genetic factors. Although epidemiological studies have shown that OA is not an inevitable event of aging but has a strong genetic component (Stecher 1941; Kellgren et al. 1963; Spector et al. 1996; Hirsh et al. 1998; Felson et al. 1998), its nature is poorly understood. A number of genes can be considered as susceptibility loci for OA, given their postulated roles in established cartilage metabolism pathways; only a few of these have been previously examined, however (Hull and Pope 1989; Meulenbelt et al. 1997, 1998; Horton et al. 1998; Ushiyama et al. 1998).

Sulfation of extracellular matrix proteins in articular cartilage is an important step in maintaining normal cartilage metabolism. Two sulfation-related genes have been reported as the causal genes of severe chondrodysplasias in human and mouse. Mutations in PAPSS2 (3'phosphoadenosine $5^{\prime}$-phosphosulfate synthase 2) cause spondylo-epimetaphyseal dysplasia (SEMD) (ul Haque et al. 1998). Mutations in SLC26A2 (solute carrier family 26, member 2) are responsible for diastrophic dysplasia (DTD) (Hastbacka et al. 1994), and an Slc26a2 mutation has been found in the brachymorphic mouse (Sugahara and Schwartz 1979). These chondrodysplasias usually show early degen- 
erative changes in articular cartilage in multiple joints and thus can be considered monogenic models of idiopathic OA. PAPSS2 protein possesses both ATP sulfurylase and adenosine $5^{\prime}$-phosphosulfate (APS) kinase activities and generates $3^{\prime}$-phosphoadenosine $5^{\prime}$-phosphosulfate (PAPS), the universal sulfate donor used in all known posttranslational sulfation reactions (Geller et al. 1987; Xu et al. 2000). SLC26A2 is a transmembrane glycoprotein with sulfate transporter activity (Hastbacka et al. 1994). In articular cartilage, proteoglycans such as aggrecan are main targets for sulfation. Aggrecan is the most abundant noncollagenous component of articular cartilage. Due to the high concentration of negative charge resulting from sulfation of its side chains, aggrecan provides articular cartilage with compressive properties and resiliency. Several studies have revealed changes in the sulfation status of proteoglycans in joints affected by conditions such as OA (Plaas et al. 1998; Bayliss et al. 2000).

Together, these findings implicate PAPSS2 and $S L C 26 A 2$ as candidate susceptibility loci for OA. To examine this possibility, we identified sequence variations in these two genes and examined the potential association of these genes with knee OA in the Japanese population.

\section{Subjects and methods}

\section{Sample collection}

One hundred and sixty-five knee OA patients and 127 controls were selected from the population participating in the Genetic Study Program of Bone and Joint Disease at Tokyo University Hospital and related institutions. The control population consisted of volunteers who had undergone treatment for injuries or other orthopedic diseases. To minimize population admixture, all individuals included in this study were Japanese, living in or around Tokyo. The study protocol was approved by the ethical committees of the participating institutions, and written informed consent was obtained from each participant. Blood samples were obtained from all participants, and genomic DNAs were prepared from peripheral leukocytes according to standard protocols.

\section{Assessment of OA}

Knee OA was assessed by physical examination and confirmed by radiographs. For each patient, standard threedirection knee radiographs (anteroposterior, lateral, and skyline views) were taken and assessed by a single expert observer (AF). To assess OA, we used a new radiographic scale (Table 1), which is a modification of the Kellgren scale (Kellgren and Lawrence 1957). The Kellgren scale has been widely used in previous genetic studies; however, it is not suitable for the genetic association study. Originally invented for population-based epidemiological studies, the Kellgren scale estimates osteophytes and joint-space narrowing compositely and puts emphasis on the detection of early changes in OA. The true pathogenesis of OA resides in degeneration and subsequent loss of articular cartilage, however; osteophytes only reflect the reactive change. The dominance of osteophytes in diagnosing radiographic OA using the Kellgren scale has been pointed out (Hart and Spector 1995; Uitterlinden et al. 1997). In contrast, our new three-part scale emphasizes joint-space narrowing and estimates the severity of osteophytes independently. The primary scale is based on estimations of the severity of joint-space narrowing, and osteophyte severity and the involvement of the patellofemoral joint are estimated independently to use as secondary scales. This simple, clear-cut system allows us to evaluate the pathologic status of the OA joint more directly, and is useful for classifying the more severe cases. A population rich in severe phenotypes might raise the statistical power of a case-control association study, because the population could have stronger genetic backgrounds (Lander and Schork 1994). Therefore, we believe that our new radiographic scale is more useful for case-control association studies.

A diagnosis of OA was confirmed by detection of jointspace narrowing of grade 3 or more by this scale. Therefore, only symptomatic and definite radiographic OA was included in the study. We excluded rheumatoid arthritis and other polyarthritis caused by autoimmune diseases, as well as post-traumatic OA and infection-induced OA. We also excluded chondrodysplasias on the basis of the presence of short stature, positive family history, and involvement of multiple joints.

Table 1. A new radiographic scale for the evaluation of osteoarthritis

\begin{tabular}{|c|c|c|c|c|c|}
\hline \multicolumn{2}{|c|}{ Main scale } & \multicolumn{4}{|c|}{ Additional scales } \\
\hline Grade & Joint-space narrowing & Grade & Osteophytes & Grade & Patello-femoral joint \\
\hline 1 & Minimal & 1 & None & 1 & No evidence of OA \\
\hline 2 & Definite, but more than half of the nornal joint remains & 2 & Minimal & 2 & Osteophytes or joint-space narrowing \\
\hline 3 & Less than half of the normal joint remains & 3 & Definite but small & & \\
\hline 4 & Diminished & 4 & Massive & & \\
\hline 5 & Loss of bone stock around the joint & & & & \\
\hline
\end{tabular}


Identification of polymorphisms in PAPSS2 and SLC26A2

A total of 16 knee OA patients were initially screened for nucleotide sequence variations in PAPSS2 and SLC26A2. The exon-intron junction and the transcription start site of PAPSS2 had been previously determined (Xu et al. 2000), and the reference sequence was obtained from the GenBank database (AF160505-9). All 12 exons and their flanking regions, as well as a $1-\mathrm{kb}$ sequence upstream of the transcription start site, were analyzed by direct sequencing of polymerase chain reaction (PCR) products from genomic DNA. Because the precise genomic structure of SLC26A2 had not been previously determined, exon-intron junctions were predicted by comparing the mRNA sequence (U14528) and the genomic sequence (AC008427) in the public database. We analyzed the two predicted exons of $S L C 26 A 2$ and their flanking regions, as well as a $1-\mathrm{kb}$ sequence upstream of the transcription start site, by direct sequencing. The primer sets used for PCR (Table 2) were designed using the Primer3 program (http://wwwgenome.wi.mit.edu/genome_software/other/primer3.html). Amplification was carried out as follows: initial denaturation at $94^{\circ} \mathrm{C}$ for $5 \mathrm{~min}$, followed by 35 cycles of $94^{\circ} \mathrm{C}$ for $30 \mathrm{~s}$, annealing temperature for $30 \mathrm{~s}, 72^{\circ} \mathrm{C}$ for $1 \mathrm{~min}$, followed by a final extension at $72^{\circ} \mathrm{C}$ for $10 \mathrm{~min}$. Direct sequencing on both strands was performed using a BigDye Terminator cycle sequencing kit (ABI, Foster City, CA, USA) and analyzed on an ABI Prism 3700 DNA analyzer.

\section{Genotyping}

Single-nucleotide polymorphisms (SNPs) were genotyped using the TaqMan assay (ABI) in 96-well plates after optimization for each primer set (Afonina et al. 1997; Livak 1999). The reaction was run on an ABI GeneAmp PCR system $9700\left(50^{\circ} \mathrm{C}\right.$ for $2 \mathrm{~min}, 95^{\circ} \mathrm{C}$ for $10 \mathrm{~min}$, and $95^{\circ} \mathrm{C}$ for $15 \mathrm{~s}$; and $62^{\circ} \mathrm{C}$ for $1 \mathrm{~min}$, for 40 cycles) and read on an $\mathrm{ABI}$
Prism 7700 sequence detector. Complex insertion-deletion polymorphisms that could not be genotyped by the TaqMan assay were genotyped by direct sequencing.

\section{Statistical analysis}

For each identified SNP, a $\chi$-squared test was performed between knee OA and the control groups for both genotypic and allelic frequencies. Statistical significance was inferred as $P<0.05$ without Bonferonni's correction for multiple testing. The correction was not applied because when the SNP loci are in strong linkage disequilibrium with one another, the correction tends to be too conservative, yielding false negative results. The odds ratio (OR) and $95 \%$ confidence interval $(95 \% \mathrm{CI})$ were calculated with respect to the minor versus major allele. Maximumlikelihood haplotype frequencies for each gene were computed using an expectation-maximization (EM) algorithm (Excoffier and Slatkin 1995) on both the knee OA and control groups, and the population difference was calculated using a $\chi$-squared test. Computations were performed using Arlequin software (http://lgb.unige.ch/arlequin/).

\section{Results}

Characteristics of sample populations

The sample population for this study is described in Table 3 . Although the mean age of the control group was approximately four years younger than that of the knee OA group, the age of onset of the knee OA group was more than six years earlier than the mean age of the control group. Therefore, this group is considered appropriate as a non-OA control. Forty-two percent of OA patients were associated with Heberden's nodes and $46 \%$ had at least one first-

Table 2. Method for polymerase chain reaction amplification of PAPSS2 and SLC26A2

\begin{tabular}{|c|c|c|c|c|}
\hline \multirow[b]{2}{*}{ Target } & \multicolumn{2}{|l|}{ Primer $\left(5^{\prime} \rightarrow 3^{\prime}\right)$} & \multirow{2}{*}{$\begin{array}{l}\text { Product } \\
\text { size (bp) }\end{array}$} & \multirow{2}{*}{$\begin{array}{l}\text { Annealing } \\
\text { temperature }\left({ }^{\circ} \mathrm{C}\right)\end{array}$} \\
\hline & Sense & Antisense & & \\
\hline \multicolumn{5}{|l|}{ PAPSS2 } \\
\hline Promoter and exon 1 & CACCATGTGTGATGATGCTG & CACAGAGCCTCTTTCTCTTGC & 988 & 55 \\
\hline Exon 2 & TGGAAGCAAAACTGCTTATGAA & ACATCTCCCAGCCTCCTTCT & 536 & 60 \\
\hline Exon 3 & TATGAAGCCTGCTTGCTTTG & CTTCCCCTAGCAGTTGGAGA & 544 & 55 \\
\hline Exon 4 & TTTCTGGACTTTCTCTCAAGCA & GAACGTTATTGCATATGGCTGA & 509 & 55 \\
\hline Exons 5-6 & CAAGGATGGCTGTTTGACCT & ATTGATCAGCTGCCTTGTGG & 566 & 55 \\
\hline Exon 7 & AGCATAACAGGTGGGGACAC & TGGAGCACACTGTAAATGATCC & 396 & 55 \\
\hline Exon 8 & TGGATTTGGGTCTTAATGCTTC & АACATCTCCTGAGGCAAAGC & 490 & 60 \\
\hline Exons 9-10 & CCCGAGATTGGTCTAAAAGG & GGAAACAGAAAGGATCCCAGA & 2500 & 50 \\
\hline Exon 11 & CATGAAGAGTGCACGGAGTC & ACTCAGTCCACTTGGGAGCA & 513 & 60 \\
\hline Exon 12 & TGGGTCTCAAAAACCATAACCT & ACATCGCCACATTGTTTGAC & 1100 & 55 \\
\hline \multicolumn{5}{|l|}{$S L C 26 A 2$} \\
\hline Promoter & TGGCTATTTTTACCTCCTTTGTTT & AGTTCCAGATGGATCCCAGA & 1085 & 55 \\
\hline Exon 1 & TCCAAAACTGAATTCСТTTTAАСТCT & TTGAATTTTGCCTCTACССТTC & 982 & 60 \\
\hline Exon 2 & AGCTCTGACATTCTGTGATGCT & GACTCTTCCACCAAGCCAAG & 1101 & 55 \\
\hline Exon 2 & GCCTACTTGTTGGGGTTTGT & TGCCTTAAGGACAGGAATGG & 1205 & 55 \\
\hline
\end{tabular}

PAPSS2, 3'-phosphoadenosine 5'-phosphosulfate synthase 2; SLC26A2, solute carrier family 26, member 2 
Table 3. Characteristics of the study population

\begin{tabular}{|c|c|c|c|c|c|c|c|}
\hline \multirow{2}{*}{$\begin{array}{l}\text { Population } \\
\text { (Number of individuals) }\end{array}$} & \multirow{2}{*}{$\frac{\text { Sex }}{\text { Male/Female }}$} & \multirow[b]{2}{*}{ Age } & \multirow{2}{*}{$\begin{array}{l}\text { Age of } \\
\text { onset }\end{array}$} & \multirow{2}{*}{$\frac{\text { Family history }}{+/-}$} & \multirow{2}{*}{$\frac{\text { Heberden's nodes }}{+/-}$} & \multicolumn{2}{|c|}{ Radiographic grade } \\
\hline & & & & & & JSN & Osteophytes \\
\hline Knee OA (165) & $20 / 145$ & $72.1 \pm 7.0$ & $62.0 \pm 10.1$ & $76 / 89$ & $69 / 96$ & $3.5 \pm 0.6$ & $3.2 \pm 0.7$ \\
\hline Control (127) & $33 / 94$ & $68.4 \pm 8.0$ & - & - & - & - & - \\
\hline
\end{tabular}

Age and age of onset are shown by mean \pm SD (years)

JSN, joint-space narrowing

Table 4. Sequence polymorphisms in PPSS2 and SLC26A2

\begin{tabular}{|c|c|c|c|c|c|}
\hline Location & $\begin{array}{l}\text { GenBank } \\
\text { accession no. }\end{array}$ & $\begin{array}{l}\text { Position in } \\
\text { genomic sequence }\end{array}$ & Nucleotide change & $\begin{array}{l}\text { Amino acid } \\
\text { change }\end{array}$ & $\begin{array}{l}\text { Frequencies } \\
\text { in screening }\end{array}$ \\
\hline \multicolumn{6}{|l|}{ PAPSS2 } \\
\hline Promoter & AF160503 & 98 & $-656 \mathrm{~A}>\mathrm{C}$ & - & $11 / 32$ \\
\hline Promoter & AF160503 & 233 & $-521 \mathrm{delG}$ & - & $1 / 32$ \\
\hline Intron 4 & AF160505 & 1494 & IVS $4+133 \mathrm{C}>\mathrm{T}$ & - & $14 / 32$ \\
\hline Intron 7 & AF160505 & 3039 & IVS7 $+17 \mathrm{G}>\mathrm{A}$ & - & $4 / 32$ \\
\hline Intron 7 & AF160505 & 3063 & IVS7 + 41ins A & - & $4 / 32$ \\
\hline Intron 9 & AF160507 & 608 & IVS9 $+179 \mathrm{C}>\mathrm{T}$ & - & $14 / 32$ \\
\hline Intron 9 & AF160507 & 760 & IVS9 $+331 \mathrm{~A}>\mathrm{G}$ & - & $2 / 32$ \\
\hline Exon 12 & AF160509 & 1491-1499 & $3^{\prime} \mathrm{UTR}+139-148 \mathrm{del}$ or ins A or T & - & $20 / 32$ \\
\hline Exon 12 & AF160509 & 1790 & $3^{\prime} \mathrm{UTR}+438 \mathrm{insCA}$ & - & $4 / 32$ \\
\hline Exon 12 & AF160509 & 1939 & $3^{\prime} \mathrm{UTR}+587 \mathrm{C}>\mathrm{T}$ & - & $12 / 32$ \\
\hline \multicolumn{6}{|l|}{$S L C 26 A 2$} \\
\hline Promoter & AC0088427 & 10282 & -716 to -713 del $4 \mathrm{~A}$ & - & $1 / 32$ \\
\hline Promoter & AC0088427 & 9795 & $-226 \mathrm{G}>\mathrm{A}$ & - & $2 / 32$ \\
\hline Exon 2 & AC0088427 & 4777 & c. $2046 \mathrm{G}>\mathrm{A}$ & L682L & $1 / 32$ \\
\hline Exon 2 & AC0088427 & 4758 & c. $2065 \mathrm{~A}>\mathrm{T}$ & T688S & $3 / 32$ \\
\hline Exon 2 & AC0088427 & 4433 & $+170 \mathrm{C}>\mathrm{T}$ & - & $1 / 32$ \\
\hline
\end{tabular}

Positions in promoter sequences are shown for transcriptional start site $=1$

UTR, untranslated region

degree relative who also had knee OA. The mean radiographic grade estimated using joint-space narrowing was 3.5 , indicating that the group had relatively severe OA.

Sequence polymorphisms in PAPSS2 and SLC26A2

A total of 15 polymorphisms were detected in PAPSS2 and $S L C 26 A 2$ by sequencing analysis (Table 4). We identified 10 polymorphisms in PAPSS2: 7 SNPs, 2 simple insertions or deletions, and 1 complex insertion-deletion. Two of the polymorphisms resided in the promoter region, five were in introns, and three were found in the $3^{\prime}$-untranslated region (UTR). We identified no cSNPs (coding-region SNPs) in PAPSS2. In SLC26A2, we identified five polymorphisms: four SNPs and one 4-bp deletion. Two of the polymorphisms resided in the upstream region of the translation start site, two were in the coding region (cSNPs), and one was located in the $3^{\prime}$-UTR. One of the cSNPs identified was nonsynonymous (T689S). The mean interval between the neighboring SNPs was $9.7 \mathrm{~kb}$ in PAPSS 2 and $1.5 \mathrm{~kb}$ in SLC26A2.

\section{Association analysis}

Sequence polymorphisms used in the association analysis were selected by their genomic localization and allelic fre- quencies determined by the screening of polymorphisms (Table 4). We genotyped five SNPs and a complex insertion-deletion polymorphism in the $3^{\prime}$-UTR of PAPSS2; for SLC26A2, we genotyped two promoter polymorphisms and a nonsynonymous cSNP (Table 5). A promoter polymorphism in SLC26A2 showed significant association with $\mathrm{OA}$. This 4-bp adenine deletion allele, del4A, was overrepresented in the OA group $(P=0.043$, odds ratio $=3.43$ ). Other biallelic polymorphisms showed no significant difference between the $\mathrm{OA}$ and control groups. We identified seven different alleles of the complex insertion-deletion polymorphism in the $3^{\prime}$-UTR of PAPSS2 (delA, delT, insA and delT, delAT, insAT, and insATA), but we found no differences in this polymorphism between the knee OA and control groups. All polymorphisms were in Hardy-Weinberg equilibrium.

\section{Haplotype analysis}

Haplotype 211 in $S L C 26 A 2$, representing the combination of the del4A allele and the major alleles of two other loci, was significantly overrepresented in the OA population (Table 6). Because 212 and 221 haplotypes were not observed, however, the 211 haplotype was thought to simply reflect the del4A allele itself. No PAPSS2 haplotypes were associated with OA. 
Table 5. Association analysis of PAPSS2 and SLC26A2 (bi-allelic polymorphisms)

\begin{tabular}{|c|c|c|c|c|c|c|c|c|}
\hline \multirow[b]{2}{*}{ Gene } & \multirow[b]{2}{*}{ Location } & \multirow[b]{2}{*}{ Nucleotide change } & \multicolumn{2}{|c|}{ Genotype (11/12/22) } & \multicolumn{2}{|c|}{ Allelic frequencies } & \multirow{2}{*}{$\frac{\chi \text {-squared test }}{P \text { value }}$} & \multirow{2}{*}{$\frac{\text { Odds ratio }}{(95 \% \mathrm{CI})}$} \\
\hline & & & $\mathrm{OA}$ & Control & $\mathrm{OA}$ & Control & & \\
\hline PAPSS2 & Promoter & $-656 \mathrm{~A}>\mathrm{C}$ & $56 / 83 / 26$ & $47 / 59 / 21$ & 0.41 & 0.40 & 0.78 & $1.05(0.75-1.46)$ \\
\hline PAPSS2 & Intron 4 & IVS4 $+133 \mathrm{C}>\mathrm{T}$ & $61 / 83 / 21$ & $47 / 57 / 23$ & 0.38 & 0.41 & 0.51 & $0.89(0.64-1.25)$ \\
\hline PAPSS2 & Intron 7 & IVS7 + 17G > A & $129 / 34 / 2$ & $100 / 25 / 2$ & 0.12 & 0.11 & 0.97 & $1.01(0.60-1.25)$ \\
\hline PAPSS2 & Intron 9 & IVS9 $+179 \mathrm{C}>\mathrm{T}$ & $41 / 82 / 42$ & $42 / 60 / 25$ & 0.50 & 0.43 & 0.093 & $1.33(0.95-1.84)$ \\
\hline PAPSS2 & Exon 12 & $3^{\prime}-\mathrm{UTR}+587 \mathrm{C}>\mathrm{T}$ & $68 / 79 / 17$ & $46 / 64 / 17$ & 0.34 & 0.39 & 0.28 & $0.83(0.59-1.16)$ \\
\hline$S L C 26 A 2$ & Promoter & -716 to -713 del $4 \mathrm{~A}$ & $152 / 13 / 0$ & $124 / 3 / 0$ & 0.039 & 0.012 & 0.043 & $3.43(0.97-12.17)$ \\
\hline$S L C 26 A 2$ & Promoter & $-226 \mathrm{G}>\mathrm{A}$ & $142 / 22 / 1$ & $107 / 20 / 0$ & 0.073 & 0.079 & 0.78 & $0.92(0.49-1.70)$ \\
\hline$S L C 26 A 2$ & Exon 2 & c. $2065 \mathrm{~A}>\mathrm{T}$ & $141 / 23 / 1$ & $107 / 20 / 0$ & 0.076 & 0.079 & 0.89 & $0.96(0.52-1.77)$ \\
\hline
\end{tabular}

"11" and "22" under Genotype denote homozygotes of the major and minor alleles, respectively. "12" denotes heterozygotes

CI, confidence interval

Table 6. Haplotype analysis of PAPSS2 and SLC26A2

\begin{tabular}{|c|c|c|c|c|}
\hline \multirow[b]{3}{*}{ Haplotype } & \multicolumn{2}{|c|}{$\begin{array}{l}\text { Haplotype } \\
\text { frequencies }\end{array}$} & \multirow{3}{*}{$\begin{array}{l}\chi \text {-squared test } \\
P \text { value }\end{array}$} & \multirow{3}{*}{$\frac{\text { Odds ratio }}{(95 \% \mathrm{CI})}$} \\
\hline & \multirow{2}{*}{$\begin{array}{l}\text { KOA } \\
N=165\end{array}$} & \multirow{2}{*}{$\begin{array}{l}\text { Control } \\
N=127\end{array}$} & & \\
\hline & & & & \\
\hline \multicolumn{5}{|l|}{ PAPSS2 } \\
\hline 111121 & 0.040 & 0.049 & 0.64 & $0.83(0.37-1.84)$ \\
\hline 111131 & 0.032 & 0.040 & 0.70 & $0.84(0.35-2.01)$ \\
\hline 111221 & 0.117 & 0.099 & 0.45 & $1.23(0.72-2.09)$ \\
\hline 111231 & 0.091 & 0.098 & 0.76 & $0.92(0.52-1.60)$ \\
\hline 222231 & 0.048 & 0.040 & 0.60 & $1.24(0.55-2.79)$ \\
\hline 121112 & 0.185 & 0.219 & 0.29 & $0.8(0.53-1.20)$ \\
\hline 211221 & 0.110 & 0.080 & 0.22 & $1.43(0.81-2.54)$ \\
\hline 211231 & 0.049 & 0.061 & 0.45 & $0.76(0.37-1.55)$ \\
\hline 212231 & 0.040 & 0.027 & 0.44 & $1.45(0.57-3.68)$ \\
\hline 221112 & 0.103 & 0.131 & 0.31 & $0.77(0.46-1.28)$ \\
\hline Others & 0.183 & 0.155 & - & - \\
\hline \multicolumn{5}{|l|}{$S L C 26 A 2$} \\
\hline 111 & 0.88 & 0.91 & 0.34 & $0.77(0.44-1.32)$ \\
\hline 122 & 0.073 & 0.079 & 0.78 & $0.92(0.49-1.70)$ \\
\hline 211 & 0.039 & 0.012 & 0.043 & $3.43(0.97-12.17)$ \\
\hline
\end{tabular}

All haplotypes that showed allelic frequencies greater than $3 \%$ in either population are shown

" 1 " denotes the major allele and " 2 " the minor allele

Each locus is shown from left to right, $-656 \mathrm{~A}>\mathrm{C}$, IVS4 $+133 \mathrm{C}>\mathrm{T}$,

IVS7 + 17G $>$ A, IVS9 + 179C $>$ T, $3^{\prime}$ UTR $+139-148$ del or ins A or

$\mathrm{T}, 3^{\prime} \mathrm{UTR}+587 \mathrm{C}>\mathrm{T}$ in PAPSS 2 , and -716 to $-713 \mathrm{del} 4 \mathrm{~A},-226 \mathrm{G}>$

A, T688S in $S L C 26 A 2$

In the 5th locus of PAPSS 2,3 'UTR del-ins A or T, "1" denotes the wild-type allele, " 2 " the delA allele, and " 3 " the delT allele

\section{Discussion}

In this study, we identified 15 DNA polymorphisms in two sulfation-related genes, PAPSS2 and SLC26A2. Our study shows that a minor polymorphism in the promoter region of $S L C 26 A 2$, del4A, was significantly overrepresented in patients with knee OA compared with the control. Because this polymorphism lies within the upstream region of $S L C 26 A 2$ and has considerable sequence changes, it seems likely that $S L C 26 A 2$ is expressed differently between the two alleles.

The del4A allele has only a minor contributing effect on knee OA, however. Its frequency is only $4 \%$, even in the population with the disease, reducing the statistical power to detect the population difference at this locus. The $P$ value from a two-sided exact test showed only marginal significance, and the $95 \%$ CI was too wide to confirm the association. Therefore, it is more appropriate to state that this risk allele showed only suggestive association. In addition, we found no differences in clinical features between the knee OA patients with/without the del4A allele, including age of onset, family history, Heberden's nodes, and radiographic grade. Further association analyses in larger populations or functional analyses will be needed to determine the true significance of the polymorphism.

We found no population difference between knee OA and the control group in our haplotype analysis, so we have excluded PAPSS 2 and $S L C 26 A 2$ as major susceptibility loci for knee OA in the Japanese population. Haplotype analysis is a powerful tool for detecting small genetic differences between two populations and predicting unknown sequence variants associated with common polygenic diseases (Jeunemaitre et al. 1997; Chakravarti 1999). Although we did not examine relatively rare polymorphisms, the negative results of our haplotype analysis justify this strategy.

Sulfate conjugation is an important pathway in the biotransformation of a number of exogenous and endogenous compounds. Many hormones, neurotransmitters, carbohydrates, and drugs are included in this pathway (Leyh 1993). PAPSS2 and SLC26A2 are expressed ubiquitously in systemic organs (Hastbacka et al. 1994; Xu et al. 2000). Polymorphisms detected in this study may affect other systemic functions such as drug sensitivity. As such, they will be useful markers in future association studies for other common diseases.

Acknowledgments We thank the patients and doctors who cooperated in this study. We also thank Mss. Akiko Kagami, Aya Narita, and Masako Ogawa for excellent technical assistance.

\section{References}

Afonina I, Zivarts M, Kutyavin I, Lukhtanov E, Gamper H, Meyer RB (1997) Efficient priming of PCR with short oligonucleotides conjugated to a minor groove binder. Nucleic Acids Res 25:2657-2660

Bayliss MT, Howat S, Davidson C, Dudhia J (2000) The organization of aggrecan in human articular cartilage. Evidence for age-related changes in the rate of aggregation of newly synthesized molecules. J Biol Chem 275:6321-6327 
Chakravarti A (1999) Population genetics-making sense out of sequence. Nat Genet 21(1 Suppl):56-60

Excoffier L, Slatkin M (1995) Maximum-likelihood estimation of molecular haplotype frequencies in a diploid population. Mol Biol Evol 12:921-927

Felson DT, Couropmitree NN, Chaisson CE, Hannan MT, Zhang Y, McAlindon TE, LaValley M, Levy D, Myers RH (1998) Evidence for a Mendelian gene in a segregation analysis of generalized radiographic osteoarthritis: the Framingham Study. Arthritis Rheum 41:1064-1071

Geller DH, Henry JG, Belch J, Schwartz NB (1987) Co-purification and characterization of ATP-sulfurylase and adenosine-5' phosphosulfate kinase from rat chondrosarcoma. J Biol Chem 262:7374-7382

Hart DJ, Spector TD (1995) Radiographic criteria for epidemiologic studies of osteoarthritis. J Rheumatol 43:46-48

Hastbacka J, de la Chapelle A, Mahtani MM, Clines G, Reeve-Daly MP, Daly M, Hamilton BA, Kusumi K, Trivedi B, Weaver A, Coloma A, Lovett M, Buckler A, Kaitila I, Lander ES (1994) The diastrophic dysplasia gene encodes a novel sulfate transporter: positional cloning by fine-structure linkage disequilibrium mapping. Cell 78:1073-1087

Hirsch R, Lethbridge-Cejku M, Hanson R, Scott WW Jr, Reichle R, Plato CC, Tobin JD, Hochberg MC (1998) Familial aggregation of osteoarthritis: data from the Baltimore Longitudinal Study on Aging. Arthritis Rheum 41:1227-1232

Horton WE Jr, Lethbridge-Cejku M, Hochberg MC, Balakir R, Precht P, Plato CC, Tobin JD, Meek L, Doege K (1998) An association between an aggrecan polymorphic allele and bilateral hand osteoarthritis in elderly white men: data from the Baltimore Longitudinal Study of Aging (BLSA). Osteoarthritis Cartilage 6:245-251

Hull R, Pope FM (1989) Osteoarthritis and cartilage collagen genes. Lancet 1(8650):1337-1338

Jeunemaitre X, Inoue I, Williams C, Charru A, Tichet J, Powers M, Sharma AM, Gimenez-Roqueplo AP, Hata A, Corvol P, Lalouel JM (1997) Haplotypes of angiotensinogen in essential hypertension. Am J Hum Genet 60:1448-1460

Kellgren JH, Lawrence JS (1957) Radiological assessment of osteoarthrosis. Ann Rheum Dis 16:494-502

Kellgren JH, Lawrence JS, Bier F (1963) Genetic factors in generarized osteo-arthrosis. Ann Rheum Dis 22:237-255

Lander ES, Schork NJ (1994) Genetic dissection of complex traits. Science 265:2037-2048
Leyh TS (1993) The physical biochemistry and molecular genetics of sulfate activation. Crit Rev Biochem Mol Biol 28:515-542

Livak KJ (1999) Allelic discrimination using fluorogenic probes and the $5^{\prime}$ nuclease assay. Genet Anal 14:143-149

Meulenbelt I, Bijkerk C, de Wildt SC, Miedema HS, Valkenburg HA, Breedveld FC, Pols HA, Te Koppele JM, Sloos VF, Hofman A, Slagboom PE, van Duijn CM (1997) Investigation of the association of the CRTM and CRTL1 genes with radiographically evident osteoarthritis in subjects from the Rotterdam study. Arthritis Rheum 40:1760-1765

Meulenbelt I, Bijkerk C, Miedema HS, Breedveld FC, Hofman A, Valkenburg HA, Pols HA, Slagboom PE, van Duijn CM (1998) A genetic association study of the IGF-1 gene and radiological osteoarthritis in a population-based cohort study (the Rotterdam Study). Ann Rheum Dis 57:371-374

Plaas AH, West LA, Wong-Palms S, Nelson FR (1998) Glycosaminoglycan sulfation in human osteoarthritis. Disease-related alterations at the non-reducing termini of chondroitin and dermatan sulfate. J Biol Chem 273(20):12642-12649

Spector TD, Cicuttini F, Baker J, Loughlin J, Hart D (1996) Genetic influences on osteoarthritis in women: a twin study. BMJ 312:940943

Stecher RM (1941) Heberden's nodes. Heredity in hypertrophic arthritis of the finger joints. Am J Med Sci 201:801-809

Sugahara K, Schwartz NB (1979) Defect in 3'-phosphoadenosine 5'phosphosulfate formation in brachymorphic mice. Proc Natl Acad Sci U S A 76:6615-6618

Uitterlinden AG, Burger H, Huang Q, Odding E, Duijn CM, Hofman A, Birkenhager JC, van Leeuwen JP, Pols HA (1997) Vitamin D receptor genotype is associated with radiographic osteoarthritis at the knee. J Clin Invest 100:259-263

ul Haque MF, King LM, Krakow D, Cantor RM, Rusiniak ME, Swank RT, Superti-Furga A, Haque S, Abbas H, Ahmad W, Ahmad M, Cohn DH (1998) Mutations in orthologous genes in human spondyloepimetaphyseal dysplasia and the brachymorphic mouse. Nat Genet 20:157-162

Ushiyama T, Ueyama H, Inoue K, Nishioka J, Ohkubo I, Hukuda S (1998) Estrogen receptor gene polymorphism and generalized osteoarthritis. J Rheumatol 25:134-137

Xu ZH, Otterness DM, Freimuth RR, Carlini EJ, Wood TC, Mitchell S, Moon E, Kim UJ, Xu JP, Siciliano MJ, Weinshilboum RM (2000) Human 3'-phosphoadenosine 5'-phosphosulfate synthetase 1 (PAPSS1) and PAPSS2: gene cloning, characterization and chromosomal localization. Biochem Biophys Res Commun 268:437-444 